\title{
Inhibition of hemolytic activity of Aeromonas salmonicida GCAT in rainbow trout red blood cells by a monoclonal antibody
}

\author{
Ingolf Lachmann*, Karl Droessler \\ Institute for Zoology, University of Leipzig, Talstrasse 33, 04103 Leipzig, Germany
}

\begin{abstract}
The present study shows that a monoclonal antibody (MAb) directed to Aeromonas salmonicida glycerophospholipid:cholesterol acyltransferase (GCAT) is capable of protecting rainbow trout red blood cells from the cytotoxic effects of the enzyme in vitro.
\end{abstract}

KEY WORDS: Aeromonas salmonicida $\cdot$ GCAT $\cdot$ Monoclonal antibody

Glycerophospholipid:cholesterol acyltransferase (GCAT) secreted by Aeromonas salmonicida ssp. salmonicida in a complex with lipopolysaccharide (LPS) has been characterized as a major lethal toxin for salmonids (Titball \& Munn 1981, Buckley 1982, Lee \& Ellis 1989, 1990, Arnesen et al. 1993, Røsjø et al. 1993, Eggset et al. 1994). It was suggested subsequently that free GCAT contributes only very little to the toxicity of the pathogen because of its tendency to form aggregates with extracellular polysaccharides (Bricknell et al. 1997). The pathogenesis of furunculosis depends on several factors, and GCAT could be only one of these. Moreover, there is evidence that GCAT-knockout mutants do not lose virulence in challenge experiments (Vipond et al. 1998). Nevertheless, the enzyme which was described as cytotoxic to Atlantic salmon (Coleman \& Huntly 1994) may be a matter of particular interest in further development of fish vaccination.

The proform of the GCAT enzyme consists of 2 polypeptides connected by a disulfide bridge and it is proteolytically digested during activation (Brumlik et al. 1997). The tendency of activated GCAT to form dimers has been documented (Ausio et al. 1993). The epitope structures of the native enzyme stimulate the immune system to develop protective activities. A

*E-mail: ilachman@gmx.de humoral immune response has to be directed to the native protein and, additionally, antibodies which inhibit enzymatic activity provide especially good protection.

This paper demonstrates that the enzyme activity of GCAT isolated from Aeromonas salmonicida and directed to rainbow trout red blood cells (RBC) can be inhibited by one murine monoclonal antibody under in vitro conditions.

For production of GCAT-containing extracellular products (ECPs), Aeromonas salmonicida strain MT004 (Ellis et al. 1988) was used and crude ECPs were prepared as described previously (Lachmann et al. 1997). GCAT was purified by anion exchange chromatography on Q Sepharose Fast Flow (QSFF) using a FPLC system (Pharmacia LKB) according to Lachmann et al. (1998).

Ammonium sulphate-precipitated ECP and purified GCAT were separated by SDS-PAGE and GCATstained by a substrate reaction as described previously (Lachmann et al. 1997). Western blotting was performed according to Towbin et al. (1979) and immunostaining of GCAT was performed using monoclonal anibodies (Mabs) or a specific rabbit anti-GCAT serum (kindly provided by J. A. Arnesen, Norwegian Institute of Fisheries and Aqualculture, Tromsø, Norway; described by Arnesen et al. 1993). Antibodies bound to GCAT were visualized using horseradish peroxidaseconjugated goat anti-mouse IgG/M and goat antirabbit IgG/M antibodies (Dianova).

Esterolytic activity of purified GCAT in solution was estimated spectrophotometrically using $1 \mathrm{mM} p$-nitrophenyl acetate (Sigma) in 0.02 M Tris-buffer, $\mathrm{pH} 7.0$, according to Kok et al. (1993). For estimation of hemolytic activity, (RBCs) from heparinized rainbow trout blood were washed 3 times in PBS ( $\mathrm{pH} 7.4)$ at $20^{\circ} \mathrm{C}$ and used in a final concentration of $1 \%(\mathrm{v} / \mathrm{v})$ in PBS. One hundred $\mu$ l of purified GCAT in PBS were 


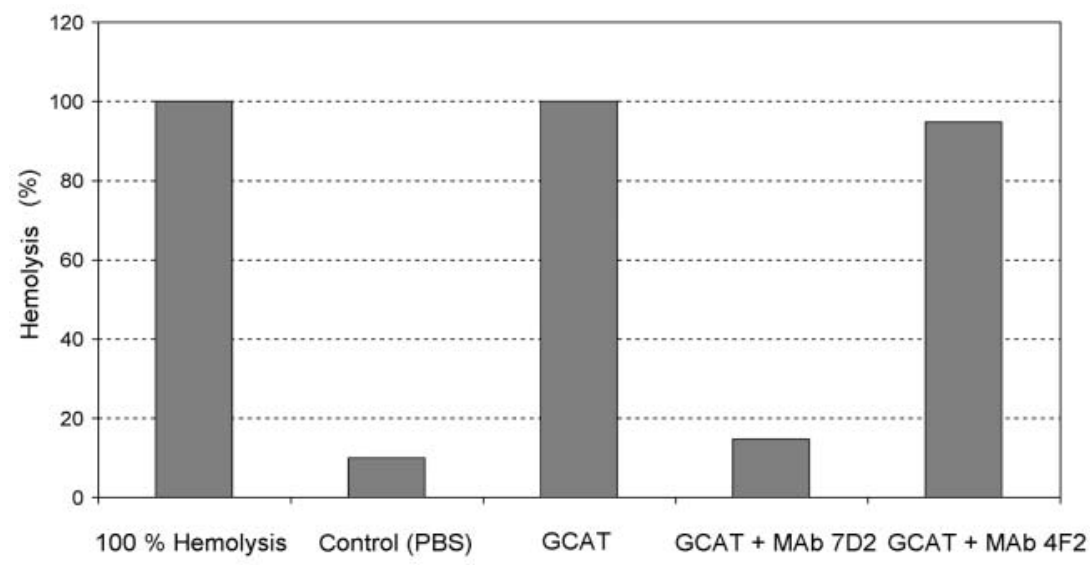

Fig. 1. Influence of pre-incubation of $1 \mu \mathrm{g}$ purified GCAT with anti-GCAT MAb 7D2 and anti-GCAT MAb 4F2 (the anti-GCAT MAbs 7D2, 4G3 and 1D11 showed similar results as $4 \mathrm{~F} 2$ ) on the hemolytic activity of the enzyme

ditions for the separation. Both purified GCAT and ECP separation resulted in 1 protein band identified by all 4 MAbs and the rabbit antiserum as GCAT (data not shown) on nitrocellulose. The band arising from ECP seemed to run slower in the native PAGE. SDS-PAGE of GCAT from crude ECP under reducing conditions followed by Western blotting revealed 3 protein bands with molecular weights of approximately 35,30 and $27 \mathrm{kDa}$ detected by the specific rabbit anti-GCAT serum from Arnesen et al. (1993). These protein bands also showed esterolytic activity. Purified GCAT was detected as the $27 \mathrm{kDa}$ molecule with esterolytic activity. Brumlick \& Buckley (1996, 1997) demonstrated trypsin activation of the proform of the enzyme (35.4 $\mathrm{kDa})$

added to $1 \mathrm{ml} \mathrm{RBC}$-suspension and incubated at $37^{\circ} \mathrm{C}$ for $1 \mathrm{~h}$. The hemolytic titres were determined spectrophotometrically as percent of the absorbance at $540 \mathrm{~nm}$ of a totally hemolysed sample according to the method of Titball \& Munn (1981). Additionally, purified GCAT (500 $\mu \mathrm{g} \mathrm{ml}^{-1}$ in PBS) was used for the estimation of the lowest quantities of protein causing 100\% hemolysis of RBC.

To analyze inhibition of hemolytic activity by antiGCAT MAbs, purified GCAT was pre-incubated with an equal volume of hybridoma supernatants containing $1 \mu \mathrm{g} \mathrm{ml}^{-1}$ anti-GCAT MAbs 4F2, 4G3, 1D11 and 7D2, which were described by Lachmann et al. (1998). An irrelevant MAb was used as negative control. The purified GCAT had a strong hemolytic effect on rainbow trout RBC. Titration showed that total hemolysis of $10^{10} \mathrm{RBC}$ was caused by $10 \mathrm{ng}$ of the purified enzyme. Pre-incubation of $1 \mu \mathrm{g}$ pure GCAT with anti-GCAT MAbs directed to different native epitopes (Lachmann et al. 1998) showed a total inhibition of hemolysis by MAb 7D2 (Fig. 1). It is conceivable that the epitope structure recognised by the inhibiting MAb 7D2 is situated close to or is otherwise related to the active site of the enzyme. MAb 4F2, 4G3 and 1D11 did not significantly inhibit hemolysis (data not shown) (Fig. 1). The MAbs reacted with native structures of the enzyme but differed in the specific epitopes recognized, as demonstrated by competition studies (Lachmann et al. 1998). MAbs 4F2 and 4G3 bound to the same structure, which seems to be a sub-structure of the epitope of MAb 1D11. It was shown that the epitope of MAb 7D2 has no relation to the epitopes of the other three MAbs. Additionally, these MAbs recognized purified GCAT or GCAT from crude ECP on nitrocellulose only using a native PAGE without SDS under non-reducing con- resulting in an excision of a $3.7 \mathrm{kDa}$ peptide. The activated GCAT contains the $27 \mathrm{kDa}$ main polypeptide bound to a smaller peptide of $4.7 \mathrm{kDa}$. Both are connected by a disulfide bridge. A 'nicking mechanism' forms the enzymatically active form of GCAT $(31.7 \mathrm{kDa})$. The 3 bands found with esterolytic activity correspond with findings of Eggset et al. (1994) describing the same properties of various GCAT forms using a protease deficient strain treated with a serine protease. The reactivity of the MAbs, in particular 7D2, with GCAT from crude ECP (Lachmann et al. 1998), and on nitrocellulose after native PAGE, does not clearly exhibit the site of the epitope on the 3 parts of the molecule, but it appears not to be on the $3.7 \mathrm{kDa}$ peptide excised by proteases.

The result of this study suggests that lytic activity of GCAT may be inhibited by a specific MAb but further studies in vivo are necessary to corroborate this theory.

Acknowledgements. The authors wish to thank Simone Hamann, Nicole Herth and Sibille Petter for their technical assistance. This work was supported by grant no. 0310616A from the German Ministry of Education, Science, Research and Technology.

\section{LITERATURE CITED}

Arnesen JA, Børnsdottir R, Jørgensen T, Eggset G (1993) Immunological responses in Atlantic salmon, Salmo salar L., against purified serine protease and haemolysins from Aeromonas salmonicida. J Fish Dis 16:409-423

Ausio J, van der Goot FG, Buckley JT (1993) Physical and chemical characterization of the oligomerization state of the Aeromonas hydrophila lipase/acyltransferase. FEBS Lett 333:296-300

Bricknell IR, Bowden TJ, Lomax J, Ellis AE (1997) Antibody 
response and protection of Atlantic salmon (Salmo salar) immunised with an extracellular polysaccharide of Aeromonas salmonicida. Fish Shellfish Immunol 7:1-16

Brumlik MJ, Buckley JT (1996) Identification of the catalytic triad of the lipase/acyltransferase from Aeromonas hydrophila. J Bacteriol 178:2060-2064

Brumlik MJ, van der Goot FG, Wong KR, Buckley JT (1997) The disulfide bond in the Aeromonas hydrophila lipase/ acyltransferase stabilizes the structure but is not required for secretion or activity. J Bacteriol 179:3116-3121

Buckley JT (1982) Substrate specificity of bacterial glycerophospholipid: cholesterol acyltransferase. Biochem 21: 6699-6703

Coleman G, Huntly PJ (1994) A histological study of the pathological effect of lipopolysaccharide-free glycerophospholipid: cholesterol acyl transferase (GCAT) on Atlantic salmon (Salmo salar L.). Biochem Soc Trans 22(4): 436

Eggset G, Børnsdottir R, McQueen Leifson R, Arnesen JA, Coucheron DH, Jørgensen T (1994) Extracellular glycerophospholipid:cholesterol acyltrans-ferase from Aeromonas salmonicida: activation by serine protease. J Fish Dis $17: 17-29$

Ellis AE, Burrows AS, Stapleton KT (1988) Lack of relationship between virulence of Aeromonas salmonicida and the putative virulence factors: A-layer, extracellular proteases and extracellular haemolysin. J Fish Dis 11:309-323

Kok RG, Christoffel VM, Vosman B, Hellingwert KJ (1993) Characterization of an esterase gene from Acinetobacter calcoaceticus BD413. J Gen Microbiol 139:2329-2342

Lachmann I, Wagner U, Haedge D, Droessler K (1997) The detection of esterolytically active glycerophospholipid: cholesterol acyltransferase of Aeromonas salmonicida in

Editorial responsibility: Carey Cunningham,

Aberdeen, Scotland, UK
SDS-polyacrylamide gels using $\alpha$-naphtyl acetate-azo dye method. J Fish Dis 20:459-461

Lachmann I, Wagner U, Haedge D, Droessler K (1998) Generation and preliminary characterisation of monoclonal antibodies directed to glycerophospholipid: cholesterol acyltransferase (GCAT) native epitopes of Aeromonas salmonicida. Dis Aquat Org 33:73-75

Lee KK, Ellis AE (1989) The quantitative relationship of lethality between extracellular protease and extracellular haemolysin of Aeromonas salmonicida in Atlantic salmon (Salmo salar L.). FEMS Microbiol Lett 61:127-132

Lee KK, Ellis AE (1990) Glycerophospholipid:cholesterol acyltransferase complexed with lipopolysaccharide (LPS) is a major lethal exotoxin and cytolysin of Aeromonas salmonicida: LPS stabilizes and enhances toxicity of the enzyme. J Bacteriol 172:5382-5393

Røsjø C, Salte R, Thomassen MS, Eggset G (1993) Glycerophospholipid: cholesterol acyltransferase complexed with lipopolysaccharide (GCAT-LPS) of Aeromonas salmonicida produces lysophospholipids in salmonid red cell membranes: a probable haemolytic mechanism. J Fish Dis 16:87-99

Titball RW, Munn CB (1981) Evidence for two haemolytic activities from Aeromonas salmonicida. FEMS Microbiol Lett 12:27-30

Towbin H, Staehelin G, Gordon J (1979) Electrophoretic transfer of proteins from polyacrylamide gels to nitrocellulose sheets. Proc Natl Acad Sci USA 76:4350-4354

Vipond R, Bricknell IR, Durant E, Bowden TJ, Ellis AE, Smith M, MacIntyre S (1998) Defined deletion mutants demonstrate that the major secreted toxins are not essential for the virulence of Aeromonas salmonicida. Infect Immun 66: 1990-1998

Submitted: July 17, 2001; Accepted: June 4, 2002

Proofs received from author(s): July 10, 2002 